\title{
POSSIBILIDADES DE INTERVENÇÃO COM O AUTISMO A PARTIR DA CIRCULAÇÃO PULSIONAL: PASSAGEM DE UMA RECUSA ATIVA À PASSIVIDADE QUE PERMITE A
PULSIONALIDADE
} Lou Muniz Atem

$\Delta \begin{gathered}\Delta \text { partir do relato de um caso, } \\ \text { gostaria de abordar algumas }\end{gathered}$ questòes suscitadas a respeito do autismo, no tocante ao seu significado em termos de estruturaçào do sujeito e à intervençòes no âmbito do tratamento. Os temas que colocarei nào dizem respeito especificamente a esse caso, mas talvez a todos para os quais não podemos ver ainda um sujeito constituído.
A associação do autismo às questòes relativas à atividade e passividade do sujeito (como sugere o título) resulta cla leitura de Freud ${ }^{1}$, bem como da proposta de Laznik-Penot (1994), a respeito do circuito pulsional. Falar da passagem da atividade à passividade primeira do encontro com o outro serve quase como uma metáfora do que acontece ao longo do circuito pulsional.

Psicóloga; psicanalista; bolsista de Aperfeiçoamento-CNPq no Laboratório de Psicopatologia Fundamental (Pós-Graduação em Psicologia Clínica-PUC/SP); aluna do Curso de Especialização na Pré-Escola Terapêutica Lugar de Vida. 
Por sua vez, falar em "atividade da recusa" alude à uma questào própria ao autismo, quando dizemos que a criança não é permeável ao contato e, mais do que isso, escapa ativamente a ele. Dizer que haja uma recusa ao outro, nào é ponto pácífico entre os psicanalistas que trabalham com autismo, mas diante do caso e da própria teoria com a qual tive contato, não vi como não incluir esse termo.

Os tópicos que trabalharei são uma tentativa de nào recusar me deixar tocar pelos sentimentos que provocam essas crianças, como, tantas vezes, já foi relatado por profissionais dessa área: o sentimento de inexistência, de impotência, de desesperança. Nào deixar que a "recusa" delas impeça a capacidade que possamos ter de compreendê-las, significa a própria possibilidade de dar continuidade ao trabalho. Compartilhar as questões e dúvidas aqui colocadas, tem este princípio como orientador.

Tiago tem 6 anos e foi, logo cedo, diagnosticado como autista pelos médicos. Atualmente, faz parte de um tratamento em grupo dirigido por psicanalistas (alguns com formação médica ou fonoaudiológica) na Pré-Escola Terapêutica Lugar de Vida. Desse grupo fazem parte dois coordenadores (da equipe da instituição) e uma estagiária (funçào que exerço), onde três tipos de atividades diferentes, por dia, sào propostas alternadamente para as crianças. Tiago participa do grupo com outras três.

Sem linguagem, com uma deficiência auditiva que ainda nào foi delimitada mas que, após alguns meses de trabalho, concordamos em pensar (a hipótese do foniatra que o atende é de que ele nào tem uma deficiência auditiva grave) que esse problema nào justifica a ausência de linguagem. Tiago é uma criança que perambula pela sala, se aproxima sempre dos mesmos objetos (cola, tesoura, fita (repe) e é difícil perceber nele um sorriso, uma brincadeira lúdica, uma demonstração de prazer com o que está fazendo. Mesmo em situaçòes em que as outras crianças riem, ele, na maior parte das vezes, permanece sério, com a cabeça parada e olhando fixo para a frente. Seu corpo escorrega ao toque, seu olhar vago, poucas vezes, encontra o nosso.

Tiago, por vezes, estarra nas pessoas como a querer encostarse ou aconchegar-se nelas e passamos a perceber que é só desta forma (através do contorno corporal) que ele pode realizar algo, produzir alguma coisa com os objetos mencionados acima. Em alguns momentos, ao vagar pela sala, ouvimos seus gritos e sons agudos, lembrando que, sempre ao entrar na sala de atividades, ele tira o aparelho auditivo. Por esse motivo, hipotetizamos que o aparelho possa estar sendo prejudicial, porque, se a deficiência auditiva não o justifica, os sons se tornarão ainda mais confusos, altos ou indiscriminados.

Com relação aos objetos, elegeu uma cadeira na qual pode sentar-se e ser perfeitamente contido ao longo de seu corpo. Em determinadas situaçòes, quando é chamado a participar, em seu 
lugar, coloca a cadeira. Também nào permite que ninguém a pegue ou sentese nela. Quando isso acontece, Tiago se desorganiza bastante, chora, grita e bate nas pessoas. No início do ano, ele aproximava- se das pessoas por trás, segurava seus pescocos e as estrangulava, intercalando essas atitudes com a de tentar escapulir da sala e correr. Aos poucos, passou a "fugir" um pouco menos e parou com os estrangulamentos. Após um tempo, começou a segurar as pessoas pelo rosto e bater com seu queixo no delas. Passamos a pensar em seus escapes da sala (e em sua forma de aproximar-se do corpo do outro através do "bater") como uma tentativa de produzir contorno corporal (como no caso das fugas, em que é necessário segurá-lo e envolvê-lo para que possa voltar).

Há pouco tempo, Tiago começou a sentar-se no chào, segurar a perna das pessoas e bater com força sua cabeça em seus joelhos ou cabeças. Notamos que utiliza sempre as partes do (orpo que são mais duras e, portanto, causam mais dor.

O menino atravessa um período em que o trabalho com ele é difícil, os escapes da sala retornam com intensidade, assim como a questào do bater, sendo muito difícil acalmá-lo quando faz isso ou quando se joga no chão mexendo o corpo e gritando. A atividade de recreação é a que permite mostrar-se mais calmo, gostando de girar e ouvir-nos cantar. Ao mesmo tempo em que essas situaçòes difíceis acontecem, suas vocalizaçòes parecem ter aumentado, e pensamos estar vendo-o fazer tentativas de verbalizar algo, como "ma, ma, ma, ma" e "be, be, be,be".

Utiliza outros objetos de modo similar ao da cadeira, assim como também o corpo do outro: de forma que deslizem, toquem e contornem seu corpo (considerando também aqui o bater e causar dor). Alguns objetos são eleitos e exercem fascínio, produzindo um certo grau de isolamento, como por exemplo um batom de cola, tinta ou canetinhas, que sào usados sobre a língua e boca, sempre ultrapassando seus contornos, e também sobre os genitais. Fazer com que os objetos estejam fundidos ou colados ao seu corpo, vem nos mostrar em que momento de sua constituiça se encontra. Sobre esse assunto, falarei mais adiante.

A equipe começa a pensar em estratégias de trabalho, como por exemplo a estratégia de contorno/deslizamento sobre seu corpo (normalmente braços e mãos) para possibilitá-lo produzir. Por outro lado, seria possível dizer que as tentativas de Tiago (assim o entendemos) de produzir o enlaçamento do outro sobre ele (como foi dito acima) seriam um modo de ele pedir por este contorno? Se essa hipótese for verdadeira, poderíamos pensar que o causar dor no próprio corpo (e não machucar o outro) seja uma forma de construção do corpo (por via da dor e nào do prazer), através da sensação causada em suas partes? Seria esta uma forma de ganhar existência psíquica (entre alguns psicanalistas, que trabalham com crianças com falhas graves de desenvolvimento, que discute-se o fato delas nào possuírem uma imagem de corpo constituída, sendo a não interaçào com o mundo uma das conseqüências disso, já que, por nào haver corpo, nào pode haver também um sujeito psíquico que responda a partir dele)? Estaria Tiago nos dizendo, com seus atos de fuga, de bater no outro, que ainda não possui um corpo e que sem ele nào pode se organizar enquanto sujeito; e que está realizando a tentativa mais dolorosa para que isso ocorra? Para que o trabalho com Tiago possa continuar, e também este texto, apesar de nunca podermos ter certeza sobre o 
fato de suas atitudes serem ou não uma forma de pedido, é preciso tomá-las como tal, já que é somente lendo em seus atos uma forma de fala que poderemos ir adiante no tratamento; apesar da constante indagaçào e sensaçào de nào saber o que essa criança produz.

Levando em conta a hipótese de que algo falhou na constituiçào de seu corpo, podemos pensar que a própria tentativa de Tiago de fazer com que o contorno corporal se dê (através de seu modo de fazer os objetos deslizarem sobre seu corpo, suas fugas, etc.) também falha, nào realiza o que pretende. O que vemos é uma seqüencia de maneiras para atingir o corpo pela dor e ligação aos objetos de modo a que eles sejam sentidos como estando fundidos ao corpo, sendo difícil diferenciar corpo/mundo externo (vide a crise de choro e fechamento autístico produzidos quando tentamos tirar um desses objetos das crianças). Vou me deter, entào, nesse último ponto: a fallha na tentativa de realizar a construção da imagem do corpo. Na verdade, uma falha, em última instância, do próprio circuito pulsional, momento do encontro do sujeito como Outro e que permitiria, justamente, pela nomeação/erogeneização que o Outro fornece, a construçào da imagem de corpo.

A primeira pergunta que poderia ser apresentada, seria (ponderando que nào quero investigar aqui a validade das hipóteses interpretativas expostas acima, mas levá-las em consideraçào já que o próprio modo relacional de Tiago nos permite pensar que de fato algo falha): que condiçòes permitem que um significante possa cumprir a função de significar e ser estruturante para alguém?

A partir dessa pergunta, e na tentativa de circundá-la, gostaria de remeter-me à teoria das pulsòes e tentar expor o chamado circuito pulsional.

Seguindo o texto freudiano Os instintos e suas vicissitudes, vemos que o trajeto de uma pulsào ${ }^{2}$ pode ser descrito da seguinte maneira: primeiramente uma pessoa é escolhida como objeto da pulsào. Nesse momento, o sujeito da pulsào fica em condiçòes de se posicionar ativamente, já que uma outra pessoá é que tomará o lugar do objeto. Em seguida, esse objeto é abandonado è a pulsào retorna ao eu do indivíduo, havendo entào para esse indivíduo uma mudança da posiçào ativa (de escolher um objeto) para a reflexiva (ser ele mesmo o objeto e o agente da pulsão). Em um terceiro momento, uma pessoa é novamente escolhida como objeto, mas, paradoxalmente, ao contrário de situar-se na relaçào como objeto, ela deve agora situar-se como ativo/agente, em razào da alteraçào do movimento da pulsào ocorrida no segundo momento. Sendo assim, ao final do circuito pulsional o sujeito ocuparia a posiçào passiva e o outro, a ativa.

É preciso diferenciar o modo como Freud, neste momento, fala do sujeito (sendo este, aquele que é ativo, agente, o lugar de onde parte a açào), do sentido propriamente dito da palavra sujeito, que vem de passividade, do estar sujeito a uma ação externa. 
Com a ajuda do filósofo Gerard Lebrun, gostaria de tentar esclarecer um pouco este conceito de passividade. "Diz-se paciente aquele que tem a causa de sua modificação em outra coisa que não ele mesmo. A potência que caracteriza o paciente nào é um poderoperar, mas um poder- tornar-se... A potência passiva está, então, em receber a forma. O paciente como tal é que é, por natureza, um ser mutável, caracterizado pelo movimento" 3 (1987,p.18). Ao contrário do que estamos acostumados a pensar, seria preciso levar em conta o sentido de paciente/passivo: em vez de um ser que não realiza ações, mas é dominado por elas, um ser que faz a essência do movimento de mutação interna, aquele que pode mudar justamente por se deixar agir de acordo com um movimento, o qual culmina com uma "mudança de forma" deste ser. Não seria justamente esta a mudança que ocorre com o sujeito da pulsào, quando se deixa afetar pelo contato com o outro?

Freud não esclarece como exatamente se dá a passagem da fase 2 para a fase 3, pois nada há que determine de antemào que, por haver se posicionado ativamente numa fase anterior, o indivíduo deva agora posicionar-se passivamente. O que Freud ressalta é que, ao posicionar-se passivamente (na $3^{\text {a }}$ fase), o indivíduo é ao mesmo tempo ativo, uma vez que a açào da pulsào, o seu movimento, depende dele. Freud diz que a reversão de uma pulsào da atividade para a passividade não implica nunca toda a quota do impulso pulsional, sendo que "a direçào ativá anterior persiste, em certa medida, com sua direçào passiva ulterior" (1974,p.151). Completada a $3^{\text {a }}$ fase, o indivíduo irá fruir da satisfaçào pulsional realizada por aquele que foi escolhido como objeto e que agora posiciona-se ativamente. Assim, estará obtendo satisfação pul- sional em sua forma passiva e ativa, essa última como o que restou de seu posicionamento inicial na 1a fase e também por identificação com o objeto escolhido. Seria de se concluir, então, que há uma transformação no caráter de atividade/passividade da pulsão e, portanto, no posicionamento do sujeito, mas ela não é levada a cabo, nunca sendo total.

O interessante é nos perguntarmos o que, apesar da pulsão não se transformar por inteiro, faz com que Freud afirme que aquele que no início era o "sujeito" da pulsão, ao final do circuito, acabe posicionando-se como objeto. $\mathrm{O}$ que leva a essa transformação e por que uma certa posiçào subjetiva (passiva) prevalece em determinado momento sobre outra (ativa)? A partir das questòes levantadas por Laznik sobre o trajeto das pulsões, poderemos investigar um pouco a este respeito.

Como primeira hipótese, pensaria em algo que Freud nào menciona claramente neste texto, que é justamente o efeito que o primeiro encontro com o Outro tem para o sujeito. Por essa interferência, ocorre a "mudança de forma" relativa à passividade citada anteriormente, através dela, à primeira vista sutil e sem efeitos, o ser torna-se capaz de modificar-se, ser caracterizado pelo "movimento", efeito este, com tantas conseqüências, que pode mudar todo o modo de estruturaçào de um sujeito.

A pulsão, diz Laznik (1994, p.4243), só pode realizar sua função quando volta-se novamente sobre o outro, completando assim seu circuito. Qual seria essa função? Seguindo a autora, no terceiro tempo do processo pulsional ocorre um assujeitamento ao outro, onde a pessoa faz dela mesma objeto da ação e, portanto, do desejo de um outro. Considero importante, no caso citado, o momento em que Tiago cai de uma certa altura batendo o queixo com força. Ele então chora e coloca-se aos 
cuidados dos outros à sua volta, situaçâo que raramente vemos acontecer. Podemos aproximar esse acontecimento de um momento de adoecimento, uma maneira que ele encontra de realizar a possibilidade do "cair" 4 (ainda que não seja um cair em forma de jogo), para podermos pensar o caso. Um cair que possibilita a criança assujeitar- se ao Outro.

A importância da instauração do circuito pulsional completo - a passagem pelas três fases de que fala Freud - advém do fato de que, só no terceiro momento se fará a ligação do sujeito com a pulsão do outro e que o campo da linguagem pode ser alcançado. Nesse momento, ao se adentrar no campo do outro/Outro pelo enlaçamento pulsional, começaria a constituir-se o sujeito (do inconsciente). É, pois, justamente a instauração desse tempo que irá faltar para o autista.

Trazer a questào do processo pulsional para falar do autismo, implica em articular a passagem da atividade da $1^{\text {a }}$ fase para a passividade da $3^{\text {a }}$ fase. Como articular, entào, o problema da atividade ao autismo, já que este nos remete justamente à uma imagem de isolamento, de falta de açào? Para mim, esse é um dos principais problemas em relação ao autismo e nos obriga a pensar que, ao contrário daquilo a que somos levados a crer, há na criança autista uma atividade em jogo. Há uma atividade no próprio fato da criança isolar-se ou recusar que o outro faça contato com ela, essa atividade constituiria a própria essência do fenômeno do autismo (como um modo de estar no mundo através do isolamento ativo). É algo difícil de pensar, já que a criança autista traz a imagem de alguém que nào é dono dos próprios atos, parece não estar ali quando é chamada, surda quando na verdade ouve, mas nào pode responder.

A imagem de alguém que não está ali refere-se ao fato de nào haver ainda um sujeito psíquico constituído que possa responder enquanto "eu", mas, para articular a falta do sujeito com o problema da atividade e da recusa ao outro que foi levantado acima, é preciso pensar que haja alguém para recusar, mesmo não havendo uma estrutura mínima necessária 5 . É preciso pensar em um modo muito particular de estruturaçào, difícil para nós, neuróticos, de imaginar como se dá.

Gostaria de remeter-me aqui à idéia de "insuficiência psíquica", desenvolvida pelo professor Manoel Tosta Berlink $k^{6}$, a pretexto de falar de situaçoes onde a falha nas defesas contra o que faz adoecer está colocada para o sujeito (o organismo entendido aqui como uma unidade psico-soma e onde uma insuficiência orgânica estaria denotando uma insufi(iência psíquica). Inversamente a isso, o autismo seria uma forma de super defesa contra o mundo, defesa que nào possibilita o contato (inclusive com o adoecer orgânico), que isola, sendo este talvez, o modo particular de estruturaçào do qual falava. Nessa direçào, Laznik (1997, p.60) retoma Lacan para falar do mecanismo de elisão como uma defesa própria ao sistema perceptivo, onde pode haver uma retirada maciça de investimento e a percepçào de um objeto pode subitamente cessar. Assim, se produz o fechamento autístico, um afastamento onde o organismo age como se algo nào existisse, mesmo estando esse algo em sua presença.

Podemos pensar que o nào tornarse uma criança de relação advenha de uma falha na interlocuçào feita à criança, que a levaria a perguntar-se sobre si, a falar e produzir discurso (a fala propriamente dita é apenas um dos modos de discurso). Essa interlocuçào diz respeito, justamente, ao terceiro tempo da circulaçào pulsional, tempo onde ela deve estar ocorrendo. 
A falha nessa fase causa, entào, uma impossibilidade de alienaçào em relaçào à própria pulsào, já que o sujeito ativo em relaçào à pulsão, nesse momento, nào sou eu, mas o outro, como foi dito anteriormente. Falha na possibilidade de se deixar agir pelo desejo, possibilidade de ser paciente e se deixar mudar pelo contato com a ação de um outro.

O que precisa ser ressaltado aqui é: para que a funçào simbólica do significante seja estruturante deve ocorrer uma construçào imaginária. Esta é que fornecerá ao (futuro) sujeito um corpo através do qual ele possa se sentir existente, já que, segundo Laznik (1994), o sujeito só irá possuir um "eu" e um "corpo" como efeito do espaço imaginário constituído entre màe e bebê.

No caso de Tiago, a equipe de profissionais que trabalha com ele discute a necessidade da construçào de uma imagem do corpo (já que ela ainda nào constituiu-se ou está bastante perturbada), como forma de possibilitar paralelamente uma maior eficácia simbólica. Essa construção pode ser trabalhada terapeuticamente através do oferecimento de atividades que envolvam o contorno corporal, a fala e nomeaçào sobre as partes do corpo, tais como desenhos de partes do corpo, jogos de encaixe, o fazer círculos, contornos, etc., nào permitindo que a pulsào retorne sempre ao sujeito impedindo que o circuito se complete.

Havendo "outros" que propiciem a atividade e se ofereçam como interlocutores, os objetos podem ser usados como intermediários para alcançá-los (o) que nào acontece com Tiago, uma vez. que eles sào vivenciados auto-eroticamente, caso do bastào de cola/tinta; ou como extensòes/invólucro do próprio corpo, o exemplo da cadeira). Quando são intermediários para alcançar algo (no caso, o ligar-se ao adulto que situa- se na outra ponta do circuito), os objetos sào objetos de troca, intercambiáveis e, portanto, simbólicos (cf. LaznikPenot, 1994, p.44).

A possibilidade de que o objeto torne-se intercambiável é da circulaçào pulsional. Ocorrem, simultaneamente, a circulaçào pulsional/objeto intercambiável e da sua repetição podemos ver surgir uma nova criança, alguém posicionando-se de forma diferente frente ao outro que o solicita - daí podermos falar em uma saída do autismo.

A forma como Freud descreve o circuito, onde o tempo da passividade (do assujeitamento à linguagem) vem após o da atividade, traz para nós uma inversào do paradigma, já que estamos acostumados a pensar a atividade valorizada como um avanço em relaçào à passividade. Por essa inversão, é possível pensar o autismo como um paradigma dos tempos ativo e reflexivo e não mais do passivo. Essa rígida (não se movimental) ativiclade do autista é que faz com que a criança nos escape, produzindo incompreensào em sua fuga. Há, porém, uma via de entendimento se pensarmos que há neste "escape/fuga" uma intençào, um ato de ser impenetrável, mas que é dado pela possibilidade de que haja alguma brecha de penetraçào, de que a pulsão nunca seja completamente transformada, já que onde há atividade, há também passivicade. Os autistas trariam assim, em sua fuga-ativa (nos momentos em que viram a cabeca para nào nos olhar nos olhos ou tapam os ouvidos para nào ouvir), um vislumbre de compreensào de que podem ser tocados pelo outro, de que trazem em si essa potência e capacidade? É preciso pensar que sim e que, como sempre em nosso trabalho, estamos mais uma vez diante de defesas e resistências frente ao que parece ameaçador, no âmbito do humano que visa proteger-se a todo custo do sofrimento. 


\section{NOTAS}

${ }^{1} \mathrm{Em}$ Os instintos e suas vicissitudes podemos ver como Freud teoriza o trajeto da pulsão de acordo com as posiçoes ativa, reflexiva ou passiva ocupadas pelo sujeito, como veremos mais adiante.

2 Apesar de constar na traduçào o termo instinto, prefiro utilizar aquele já consagrado de pulsào.

3 Grifo meu.

${ }^{4}$ Alfredo Jerusalinsky fala do "jogo de cair" como um importante jogo de constituição do sujeito, através do qual a criança se certifica daquilo que a sustenta no mundo, as palavras, leis e cuidados dos adultos para com ela e dos limites que as coisas possuem.

${ }^{5}$ Em seminário oferecido no Instituto de Psicologia da USP, em 1996, Alfredo Jerusalinsky fala do conceito de "estruturas mínimas" de organizaçào do processo mental, onde, caso nào haja um mínimo de estruturaçào, nada pode se organizar. Penso, porém, que nessa afirmação nào está implícito que não haja nenhum sujeito psíquico envolvido. Mesmo quando uma criança se torna autista, é preciso pensar que haja um sujeito psíquico em questào.

6 Discussões realizadas no Laboratório de Psicopatologia Fundamental - PósGraduação em Psicologia Clínica (PUC-SP), ao longo do primeiro semestre de 1997.

\section{REFERÊNCIAS BIBLIOGRÁFICAS}

FREUD, S. (1974). Os instintos e suas vicissitudes. In: Ediçào Standar das Obras Completas, v. XIV, Rio de Janeiro: Imago, p. 137-162 [1915].

LAZNIK-PENOT, M-C. (1994). Do fracasso da instauraçâo da imagem do corpo ao fracasso da instauraçào do circuito pulsional. Quando a alienaçào faz falta. In: O que a clinica do autismo pode ensinar aos psicanalistas, Salvador: Ámalga, p.31-48.

LAZNIK-PENOT, M-C. (1997). Rumo à palaura: três crianças autistas em psicanálise, São Paulo: Escuta.

LEBRUN, G. (1987). O conceito de paixào. In: CARDOSO, S. et alii. Os sentidos da paixão, São Paulo: Companhia das Letras, p. 17-33. 